\title{
Correlation investigations into pollutant emission and the operational states of compression-ignition engines in dynamic tests
}

This study investigates the correlation dependences between pollutant emission intensity and the engine operational states determining these properties, in various conditions, both in relation to measurements of engine operational states and their dynamic nature. The research was carried out in a variety of dynamic tests. Investigations into the correlations of processes occurring in combustion engines make it possible to assess the impact of one process on another and the relationship between the various processes. In general, it was found that similar dependencies occur for carbon monoxide and hydrocarbons, but were often substantially different for nitrogen oxides.

Key words: combustion engines, pollutant emission, correlation analysis

\section{Introduction}

The objective of this study is to examine the correlation dependences between pollutant emission intensity and the internal combustion (IC) engine operational states determining these properties, in different conditions, both in relation to the values of the states and their dynamic nature. Diverse working conditions of IC engine are applied during engine testing, in a variety of dynamic tests.

The operational states of IC engines which determine pollutant emission from engines pre-heated to a stable temperature are described in this study by the following measures: engine rotational speed, engine torque and effective power. Pollutant emission intensity depending on engine operational states and the intensity of emission of individual pollutants relative to each other have been subjected to correlation research.

Due to the limited size of the article the published research uses only the Pearson's linear correlation [14], and reference is also made to the authors' own unpublished results using the non-parametric correlation theories Spearman's rank correlation [16], Kruskal's gamma correlation [12], and Kendall's tau correlation [10].

Most of the publications concerning correlation relationships between processes occurring in IC engines are associated with engine steering [5, 11] and diagnostics [17]. These publications are more practical than cognitive. Studies on correlation models of particulate matter emission and the quantities characterising smoke opacity [7] can also be met. In the work presented in [8] the sensitivity of pollutant emission to the different specifications of fuels in different areas of the static states of engine operation was investigated. In publication [9] the results of the analysis of particulate matter emission in the conditions of actual bus operation are presented. In that report, the results of investigations into the correlative effects of the particulate matter emission on, inter alia, engine operational states, have been published. The results of correlation investigations into pollutant emission from spark-ignition engines and compression-ignition engines have been presented in articles [4] and [3], respectively. Publication [2] deals with research into relationships between the intensity of pollutant emission from compression-ignition engines and the states de- termining the pollutant emission, carried out by employing the function of intercorrelation between the processes under investigation.

This study deals with research into pollutant emission processes and engine operational states determining the pollutant emission, in dynamic tests characterising the working conditions of compression-ignition engines in nonroad machines.

\section{Research results}

Tests were carried out on a Cummins 6C8.3 engine. It is a four-cylinder turbocharged compression-ignition engine with an $8.3 \mathrm{dm}^{3}$ capacity. This engine meets the emissionlevel requirements of Euro III. The tests were carried out within the project reported in [1]. The engine was tested on a test stand equipped with a dynamometer bench that allows the testing of engines in dynamic conditions.

Research was carried out using dynamic tests:

- NRTC (Non-Road Transient Cycle), employed in typeapproval procedures [18],

- BBDT (Bulldozer-Blade Dynamic Test) prepared within the project reported in [1],

- BRDT (Bulldozer-Ripper Dynamic Test) prepared within the project reported in [1].

BBDT and BRDT tests were developed in accordance with the principle of faithful simulations in real time [13]. The results of experiments carried out on a testing ground in the blade and ripper operating modes of a bulldozer were used for the synthesis of tests [1]. As fundamental criteria of similarity when developing the tests, the similarity of the average value and variance of the engine steering and torque in tests, and under empirical test conditions, were assumed.

Figures 1-6 show the time histories of the engine speed and torque in the individual tests. Figures 7-9 represent the set of IC engine operational states within the coordinate system: engine speed - torque, in individual tests. The points of coordinates of the average values of the engine speed and engine torque have also been marked on the graph. Figure 10 represents the points of coordinates: the average values of the engine speed and engine torque in individual tests against the background of full-load torque vs. engine speed curve. 


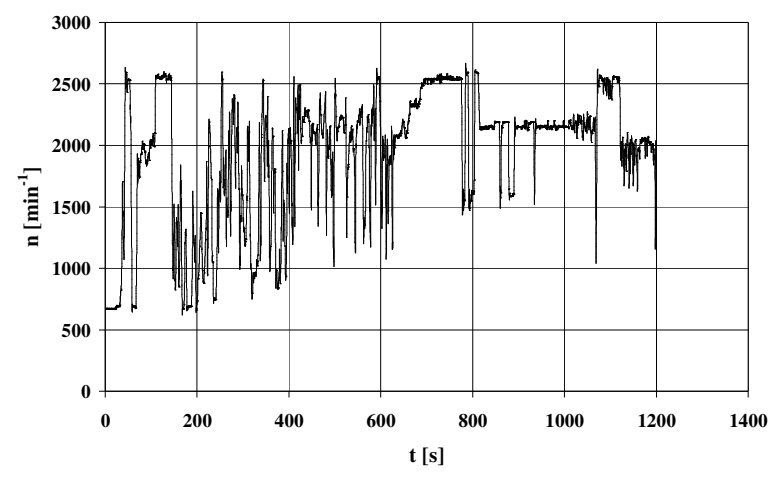

Fig. 1. Engine speed $-\mathrm{n}$ vs. time $-\mathrm{t}$ curve, recorded in the NRTC test

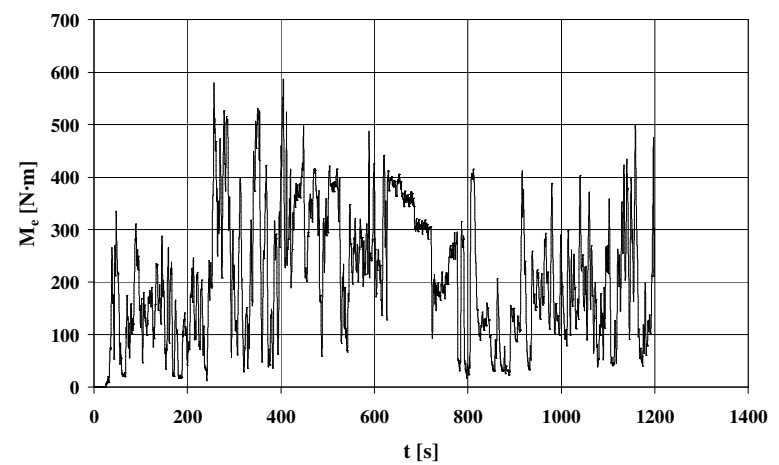

Fig. 2. Engine torque $-M_{e}$ vs. time $-t$ curve, recorded in the NRTC test

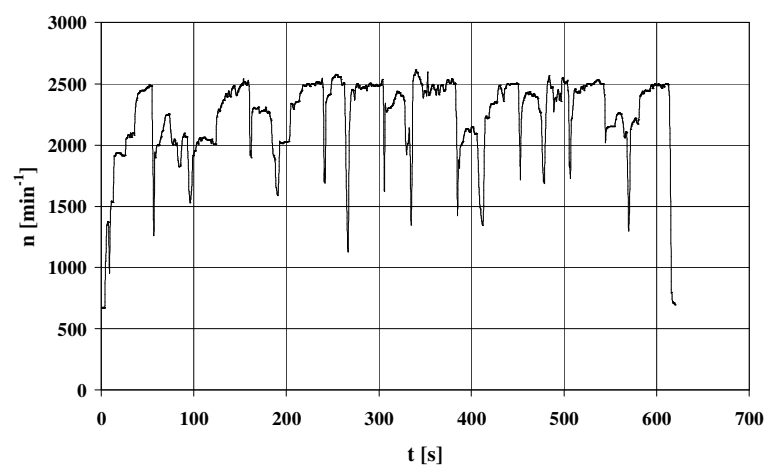

Fig. 3. Engine speed $-\mathrm{n}$ vs. time $-\mathrm{t}$ curve, recorded in the BBDT test

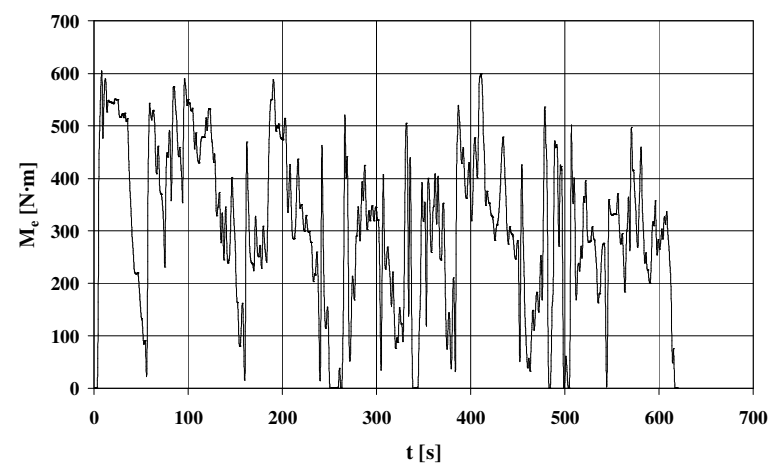

Fig. 4. Engine torque $-\mathrm{M}_{\mathrm{e}}$ vs. time $-\mathrm{t}$ curve, recorded in the BBDT test

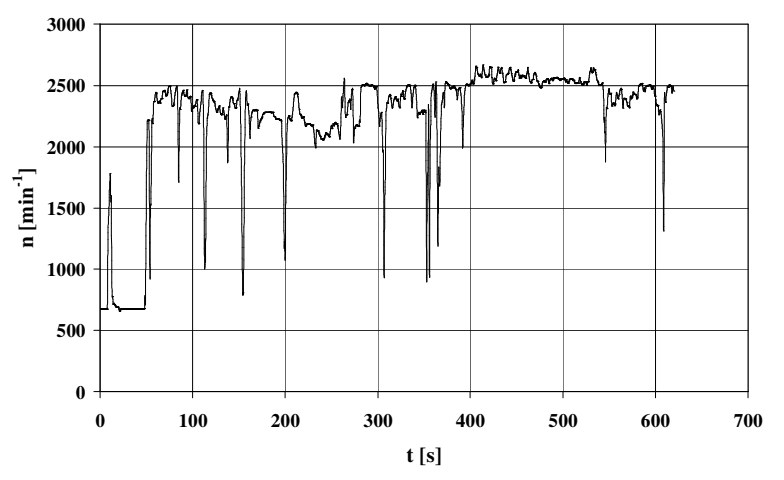

Fig. 5. Engine speed $-\mathrm{n}$ vs. time $-\mathrm{t}$ curve, recorded during the BRDT test

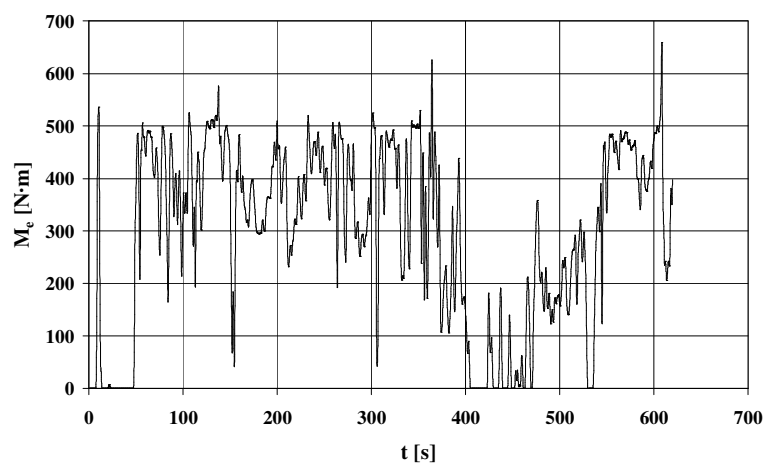

Fig. 6. Engine torque $-M_{e}$ vs. time $-t$ curve, recorded in the BRDT test

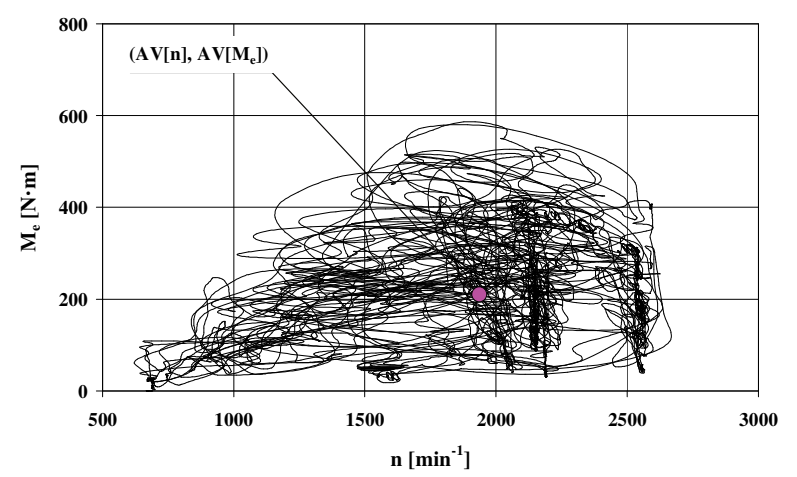

Fig. 7. The set of engine operational states: engine speed $-n$, torque $-M_{e}$ in the NRTC test; $\left(\mathrm{AV}[\mathrm{n}], \mathrm{AV}\left[\mathrm{M}_{\mathrm{e}}\right]\right)$ - the coordinates of the average values of the engine speed and engine torque

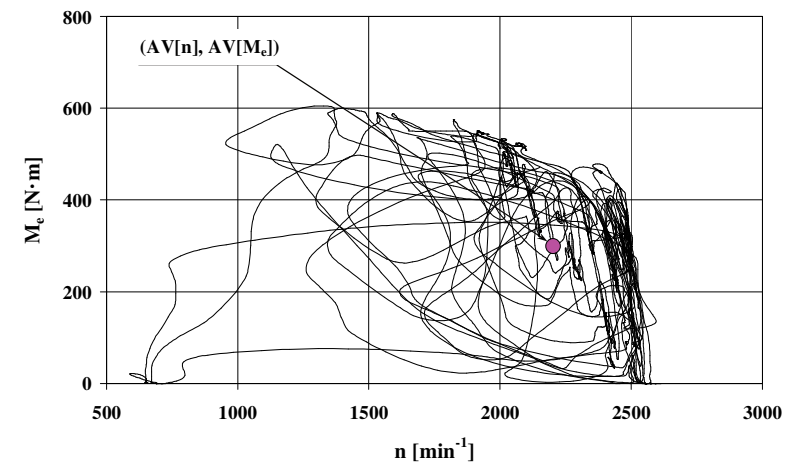

Fig. 8. The set of engine operational states: engine speed $-n$, torque $-M_{e}$ in the BBDT test; $\left(\mathrm{AV}[\mathrm{n}], \mathrm{AV}\left[\mathrm{M}_{\mathrm{e}}\right]\right)$ - the coordinates of the average values of the engine speed and engine torque 


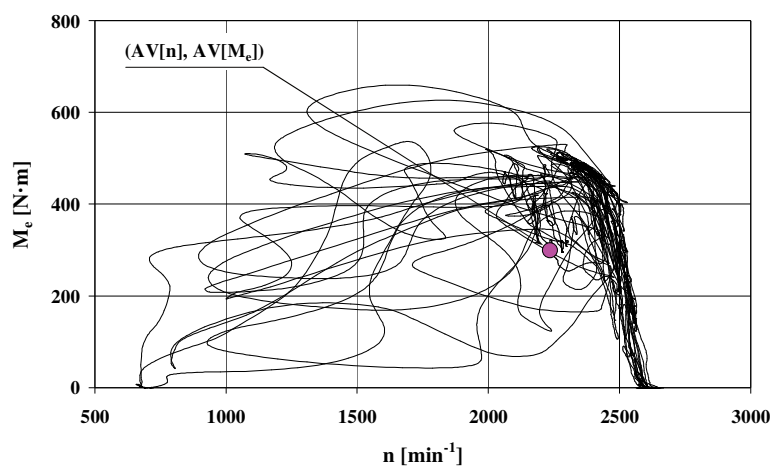

Fig. 9. The set of engine operational states engine speed $-n$, torque $-M_{e}$ in the BRDT test; $\left(\mathrm{AV}[\mathrm{n}], \mathrm{AV}\left[\mathrm{M}_{\mathrm{e}}\right]\right)$ - the coordinates of the average values of the engine speed and engine torque

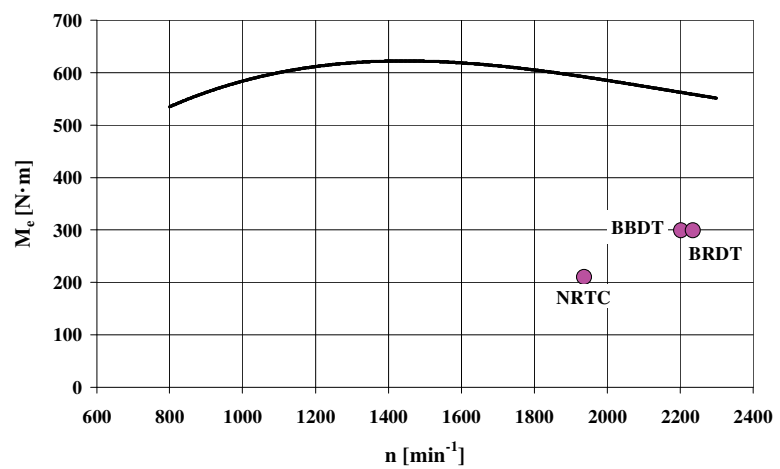

Fig. 10. Points of coordinates: the average value of the engine speed $-\mathrm{n}$, the average value of the engine torque $-M_{e}$ in tests against the background of full-load torque vs. speed curve

A big difference is clearly visible in the positions of the points of the coordinates: the average values of the engine speed and the engine torque, in individual tests. The BBDT and BRDT tests in respect of the static states of engine operation - according to the criterion of their average values - are close to each other. These tests are characterised by high speed and high loads.

The recorded signals of engine speed, engine torque and pollutant emission intensity were synchronised with taking into account the exhaust-gas tap-off location in the engineexhaust system - the delays in individual signals, related to the exhaust-gas analysis, were taken into account. The measurement sampling frequency was $10 \mathrm{~Hz}$. The signals were digitally processed to eliminate gross errors and to reduce the influence of high-frequency interference. The gross errors were identified by continuously analysing the variance of measurement results. To reduce the effects of high-frequency noise on the signals, a Golay-Savitzky lowpass filter [15] was used, with both-side approximation from 5 data points on each side to a polynomial of degree 2 being applied.

The graphs shown in Figures 11-13 represent in aggregate form the time histories of pollutant emission intensity in the tests.

Figure 14 shows the average values of pollutant emission intensity in individual tests.

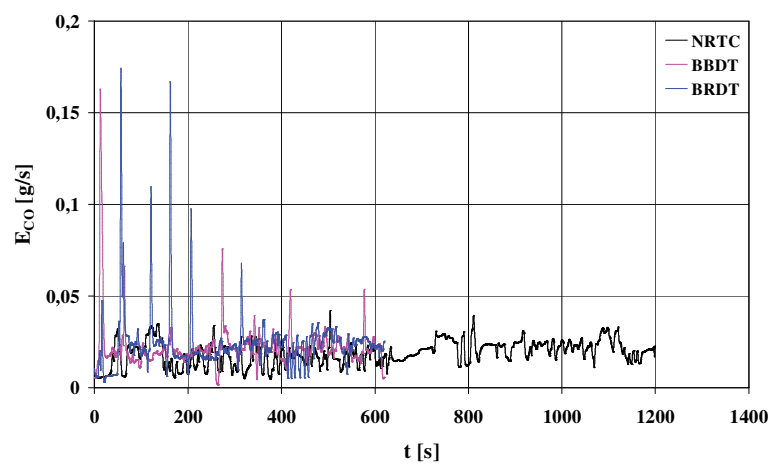

Fig. 11. Courses of the carbon monoxide emission intensity $-\mathrm{E}_{\mathrm{CO}}$ in tests

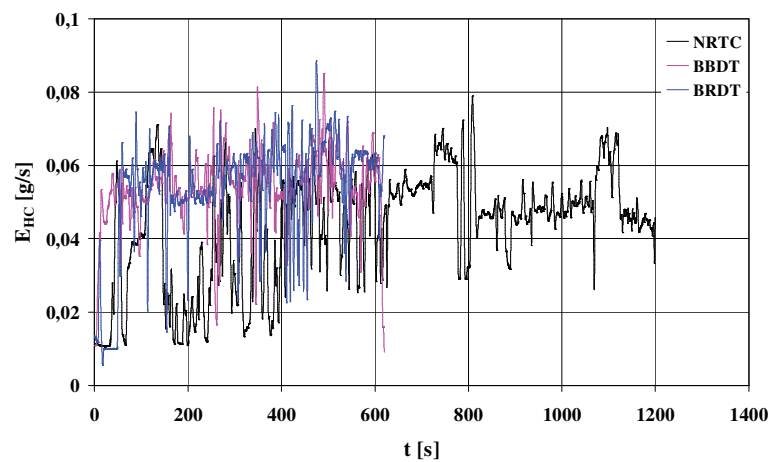

Fig. 12. Courses of the hydrocarbons emission intensity $-\mathrm{E}_{\mathrm{HC}}$ in tests

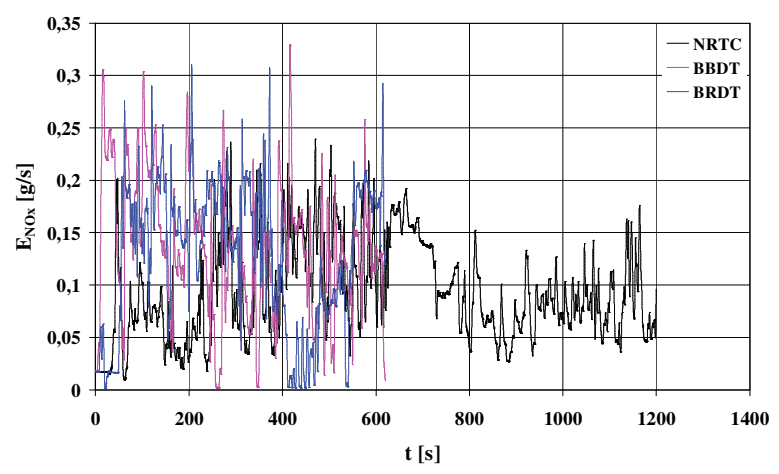

Fig. 13. Courses of the nitrogen oxides emission intensity $-\mathrm{E}_{\mathrm{NOx}}$ in tests

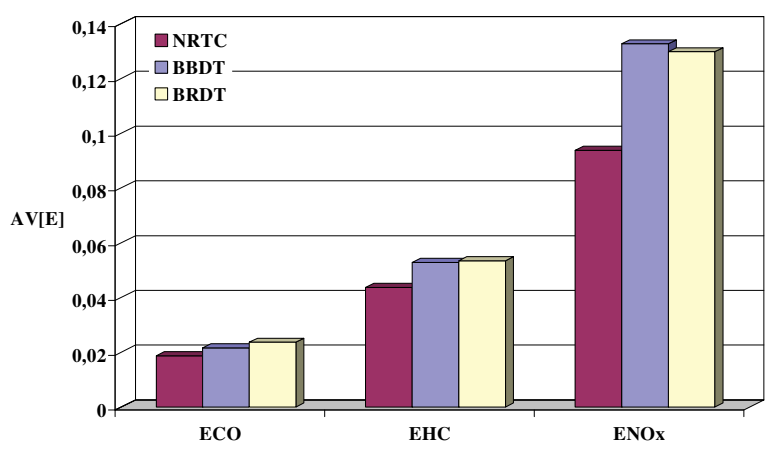

Fig. 14. The average value - AV[E] of pollutant emission intensity in individual tests 
There is a clear differentiation between the average values of the pollutant emission intensity in the various tests. Tests with a larger engine load involve larger values of average pollutant emission intensity; particularly large differences occurs in the case of nitrogen oxides. The average values of the emission intensities of individual pollutants in BBDT and BRDT tests are close to each other.

Figs. 15, 16 and 17 show, respectively, the coefficient of Pearson's linear correlation between pollutant emission intensity and engine speed, torque and effective power.

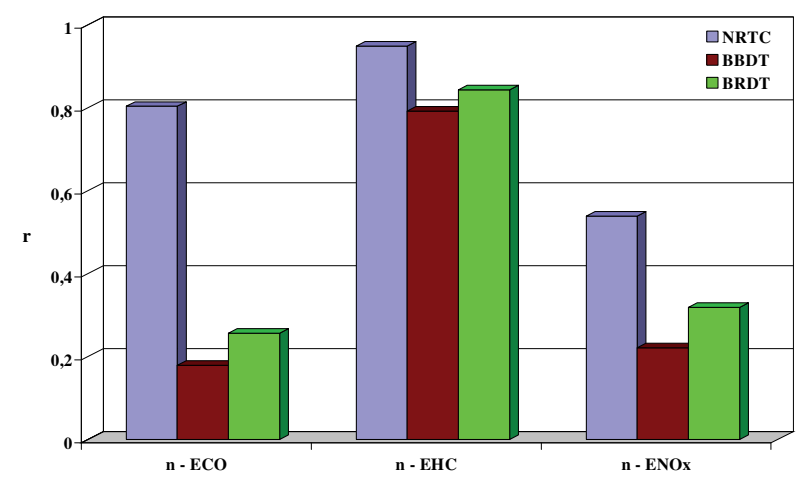

Fig. 15. The coefficient of Pearson's linear correlation $-r$ between engine speed and pollutant emission intensity in individual tests

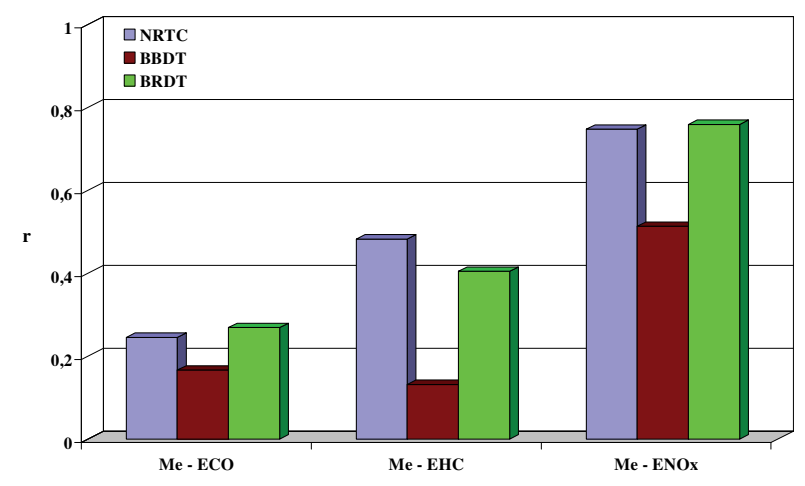

Fig. 16. The coefficient of Pearson's linear correlation $-r$ between engine torque and pollutant emission intensity in individual tests

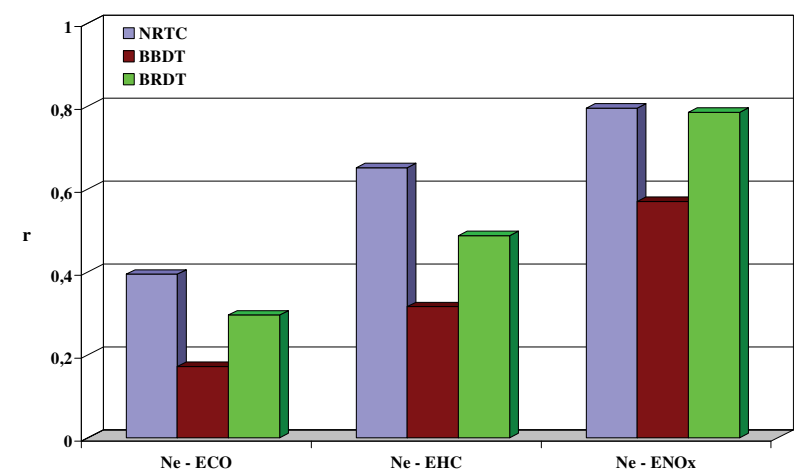

Fig. 17. The coefficient of Pearson's linear correlation $-r$ between engine effective power and pollutant emission intensity in individual test

Although the correlation coefficient values are widely diverse (they range from 0.13 to 0.95 ), the probability that the hypothesis of the absence of a correlation would not be rejected is below 0.01 , even for their lowest values. This can be explained by a very large size of the sets under investigation [6], which consist of about 12,000 elements for the NRTC test and 6,400 for the BBDT and BRDT tests.

The values of the coefficient of correlation between the engine speed and the pollutant emission intensity are the highest in NRTC test, and the lowest in the BBDT test. For torque and effective power the pattern is different: the NRTC and BRDT tests have similar correlation coefficient values, while the BBDT test has considerably lower correlation coefficient values.

Figs. 18-20 present the coefficient of the correlation between the emission intensity of individual pollutants and engine speed, torque and effective power.

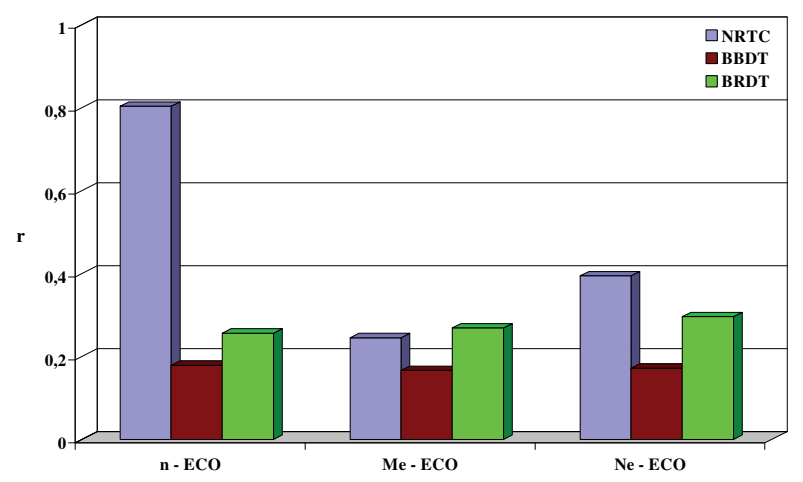

Fig. 18. The coefficient of Pearson's linear correlation $-r$ of carbon monoxide emission intensity with engine speed, torque and effective power

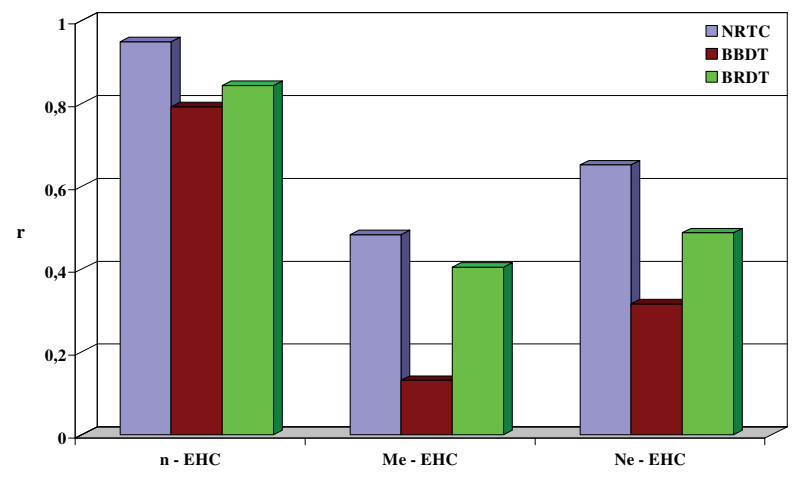

Fig. 19. The coefficient of Pearson's linear correlation $-r$ of hydrocarbons emission intensity with engine speed, torque and effective power

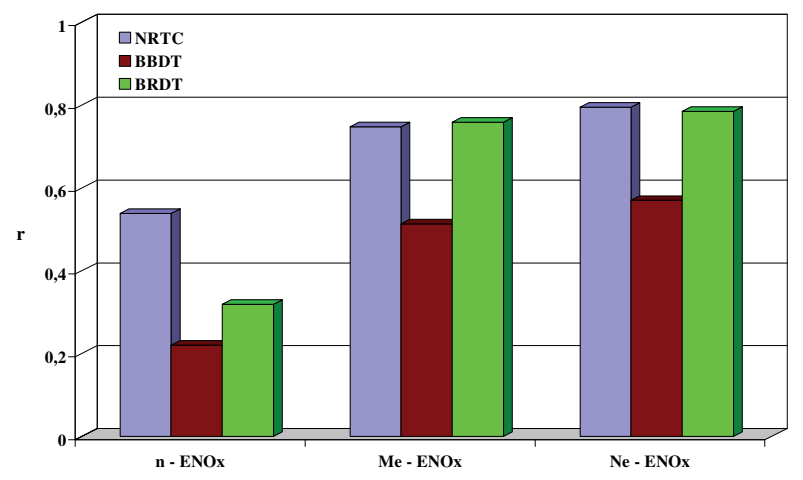

Fig. 20. The coefficient of Pearson's linear correlation $-r$ of nitrogen oxide emission intensity with engine speed, torque and effective power 
Similar trends exist for torque and effective power. It is characteristic that the dominant factor determining the emission intensity of hydrocarbons, and - less clearly - of carbon monoxide, is engine speed, whereas of nitrogen oxides - torque and effective power.

Figure 21 shows the correlation coefficient between the pollutant emission intensity in individual tests.

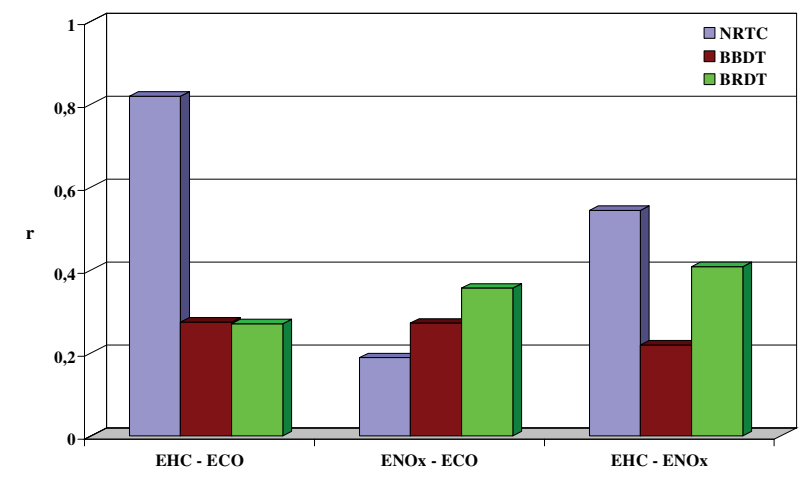

Fig. 21. The coefficient of Pearson's linear correlation $-r$ between the pollutant emission intensity in individual tests

It was found that major differences exist in the values of the correlation coefficient between the pollutant emission intensity in individual tests. Also in this case, the probability that the hypothesis of the absence of a correlation would not be rejected is below 0.01 in all pairs of sets analysed. The correlation coefficient has the highest value for the hydrocarbons emission intensity and the carbon monoxide emission intensity in the NRTC test, while the lowest was in the same test - for the carbon monoxide emission intensity and the nitrogen oxide emission intensity. In all other cases, the differences between the values of the correlation coefficient are lower. In general there is a certain similarity because of the value of the correlation coefficient in the BBDT and BRDT tests.

\section{Summary}

The research work having been carried out may be recapitulated by formulating the following conclusions:

1. Wide differences between the values of the correlation coefficient for the examined quantities in the range of
0.13 to 0.95 were found. Nevertheless, even for the smallest values, the probability that the hypothesis of the absence of a correlation would not be rejected is below 0.01 , which can be explained by the very large size of the sets under investigation.

2. The values of the correlation coefficient between the engine speed and the pollutant emission intensity are the highest in NRTC test, and the lowest in the BBDT test.

3. The NRTC and BRDT tests have the highest values of the correlation coefficient of torque and effective power with pollutant emission intensity, while the BBDT test has considerably lower correlation coefficient values.

4. The dominant factor determining the emission intensity of hydrocarbons and - less clearly - of carbon monoxide, is engine speed, whereas of nitrogen oxides - torque and effective power.

5. It was found that major differences exist in the values of the correlation coefficient between the pollutant emission intensity in individual tests: the correlation coefficient has the highest value for the hydrocarbon emission intensity and the carbon monoxide emission intensity in the NRTC test, while the lowest in the same test - for the carbon monoxide emission intensity and the nitrogen oxide emission intensity.

This paper presents the results of research using Pearson's linear correlation coefficient. Similar results can also be obtained for the coefficients of Spearman's rank correlation, Kruskal's gamma correlation, and Kendall's tau correlation.

Investigations into the correlations between the processes occurring in IC engines make it possible to assess the impact of one process on another and the relationships between the various processes. It is symptomatic of combustion engines that dynamic operating states affect in different ways the phenomenon of the emission of various pollutants. Generally, similar dependencies occur for carbon monoxide and hydrocarbons, but they are often substantially different for nitrogen oxides. The research was performed in three tests simulating the working conditions of IC engine in non-road machines. The authors' own work shows that similar trends apply in the case of other working conditions of IC engines.

\section{Nomenclature}

$\begin{array}{ll}\text { AV } & \text { average value } \\ \text { BBDT } & \text { Bulldozer-Blade Dynamic Test } \\ \text { BRDT } & \text { Bulldozer-Ripper Dynamic Test } \\ \text { E } & \text { emission intensity } \\ \mathrm{E}_{\mathrm{CO}} & \text { carbon monoxide emission intensity } \\ \mathrm{E}_{\mathrm{HC}} & \text { hydrocarbons emission intensity } \\ \mathrm{E}_{\mathrm{NOx}} & \text { nitrogen oxides emission intensity }\end{array}$

IC internal combustion

$\mathrm{M}_{\mathrm{e}} \quad$ engine torque

n engine rotational speed

NRTC non-road transient cycle

$r$ the coefficient of Pearson's linear correlation

t time

\section{Bibliography}

[1] BUDNY, E., CHŁOPEK, Z., CHŁOSTA, M. Ocena skuteczności zasilania silnika spalinowego gazem ziemnym w celu ograniczenie emisji zanieczyszczeń w warunkach użytkowania silnika w maszynie do robót ziemnych
- ciągniku gąsienicowym (The evaluation of the effectiveness of supplying of combustion engine with natural gas to reduce pollutant emission in the conditions of the engine used in an earth mover - crawler tractor). Report of research 
project No. 9 T12 D 01323 sponsored by the State Committee for Scientific Research, Warsaw 2009 (not published).

[2] CHŁOPEK, Z., SZCZEPAŃSKI, T. Correlation research of combustion engines properties in dynamic states. Combustion Engines. 2013, 154(3), 175-182.

[3] CHŁOPEK, Z. A correlation analysis of the pollutant emission from a self ignition engine. Silniki Spalinowe - Combustion Engines. 2010, 140(1), 25-32.

[4] CHŁOPEK, Z. The correlation researches of a pollution emission from the internal combustion engine. Czasopismo techniczne. Mechanika. 2004, 101(6-M), 151-156.

[5] EPA: The development of emission rates for light-duty vehicles in the motor vehicle emissions simulator (MOVES2009). Draft Report No. EPA-420-P-09-002. The U.S. Environmental Protection Agency, 2009.

[6] FISZ, M. Probability theory and mathematical statistics. Wiley. New York, 1963.

[7] JAGADISH, D., KUMAR, P.R., MURHTY, K.M. The performance and emission characteristics of diesel engines run on biofuels based on experimental and semi analytical methods. International Journal of Energy and Environment. 2011, 2(5), 899-908.

[8] JEIHOUNI, Y., PISCHINGER, S., RUHKAMP, L., KOERFER, T. The relationship between fuel properties and sensitivity analyses of non-aromatic and aromatic fuels used in a single-cylinder heavy-duty diesel engine. SAE Technical Paper. 2011, 2011-01-0333.

[9] KAMARIANAKIS, Y., GAO, H.O. Diesel ultrafine/fine particle emissions in numbers: statistical modeling and evaluation of engine operating variables. Final Report No. 49777-33-19. The University Transportation Research Center, The City College of New York. New York, 2009.

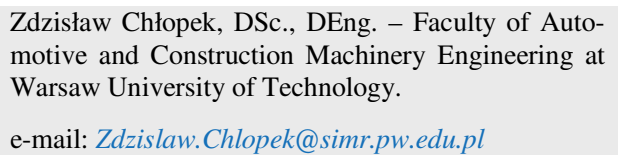

[10] KENDALL, M.G. A new measure of rank correlation. Biometrika. 1938, 30, 81-89.

[11] KITAMURA, Y., MOHAMMADI, A., ISHIYAMA, T., SHIOJI, M. Fundamental investigation of $\mathrm{NO}_{\mathrm{x}}$ formation in diesel combustion under supercharged and EGR conditions. SAE Technical Paper. 2005, 2005-01-0364.

[12] KRUSKAL, H., WALLIS, W.A. Use of ranks in onecriterion variance analysis. Journal of the American Statistical Association. 1952, 260(47), 583-621.

[13] MARECKA-CHŁOPEK, E., CHŁOPEK, Z. Synteza testów do badań silników spalinowych maszyn roboczych (A synthesis of tests for investigations into the combustion engines of non-road machines). A chapter in "Uwarunkowania ekorozwoju rekreacji i turystyki" (The conditions for the sustainable development of recreation and tourism). Wydawnictwo Naukowe Gabriel Borowski, Lublin, 2008, 258-267.

[14] PEARSON, K. On the theory of contingency and its relation to association and normal correlation. Drapers' Company Research Memoirs. Biometric Ser. I, Dulau and Co., London, 1904.

[15] SAVITZKY, A., GOLAY, M.J.E. Smoothing and differentiation of data by simplified least squares procedures. Analytical Chemistry. 1964, 36, 1627-1639.

[16] SPEARMAN, C. The proof and measurement of the association between two things. American Journal of Psychology. 1904, 15, 72-101.

[17] SUAREZ-BERTOA, R., ZARDINI, A.A., ASTORGA, C. Ammonia exhaust emissions from spark-ignition vehicles over the New European Driving Cycle. Atmospheric Environment. 2014, 97, 43-53.

[18] Worldwide emission standards. Heavy-duty \& off-road vehicles. Delphi. Innovation for the real world. 2015/2016.
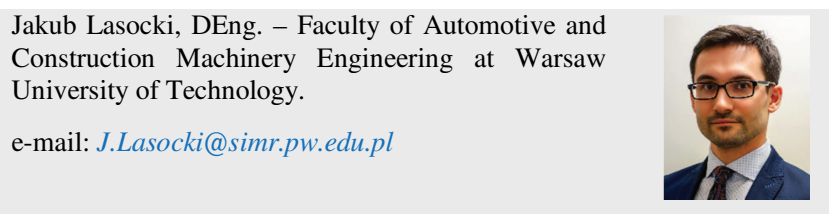